\title{
Prensa en la cuarta pantalla. Movilidad de la información del papel al bolsillo
}

\author{
Por Carmen Costa-Sánchez y María-Teresa Piñeiro-Otero
}

\begin{abstract}
Resumen: La prensa digital se encuentra inmersa en un proceso de intenso dinamismo, caracterizado por la incorporación al proceso de comunicación de las nuevas tecnologías de la comunicación y la información (TIC) y la búsqueda de nuevos modelos de negocio. En este contexto, los medios digitales han encontrado en los dispositivos móviles una de sus principales plataformas de desarrollo, dadas las posibilidades que presentan a la hora de acercar la información a sus receptores, así como individualizar los mensajes en función de sus preferencias. Se abordan las posibilidades de movilidad de la información que presentan los nuevos dispositivos móviles, así como su implantación entre los cibermedios españoles. Un análisis para el que se han tomado como referencia aquellas webs auditadas por OJD Interactiva.
\end{abstract}

Palabras-clave: Dispositivos móviles, Cuarta pantalla, Web 2.0, Noticias, Información.

Title: Press on the fourth screen. Information mobility from paper to pocket.

Abstract: Online press is immersed in a dynamic process, characterised by the incorporation of information technologies (IT) and search for new business models. In this context, digital media have found in mobile devices one of their main platforms of development, due to the possibilities of bringing information closer to its recipients and personalising messages according to their preferences. The object of this article is to investigate the potential of new mobile devices for information mobility, and their implementation for Spanish cybermedia. Pages audited with OJD Interactive software were used for this analysis.

Keywords: Mobile devices, Fourth screen, Web 2.0, News, information.

Costa-Sánchez, Carmen; Piñeiro-Otero, María-Teresa. "Prensa en la cuarta pantalla. Movilidad de la información del papel al bolsillo". El profesional de la información, 2010, noviembre-diciembre, v. 19, n. 6, pp. 632-636.

DOI: 10.3145/epi.2010.nov.09

\section{La cuarta pantalla, posibilidades para la movilidad de la información}

El teléfono móvil se ha acomodado en nuestras vidas. El denominado mobile device o cuarta pantalla, el medio más próximo y personal, se ha incorporado a nuestros usos y costumbres diarios en un tiempo récord. En apenas diez años la tasa de penetración de la telefonía móvil en España se ha incrementado en un $90 \%$, pasando de un $10,7 \%$ en 1997 a un $107,6 \%$ en 2008.

No sólo se ha ampliado el número de usuarios, sino que su perfil se ha diversificado. Se potencia su uso entre públicos cada vez más jóvenes gracias a unos receptores a bajo precio junto a unas tarifas relativamente asequibles a todos los bolsillos.
Se han ampliado asimismo sus posibilidades de uso y los contextos en los que se utiliza. La cuarta pantalla llena los tiempos muertos de las esperas y de los trayectos en transporte público, ocupa nuestros ratos de ocio y se ha convertido en plataforma de acceso a aquella información que más nos interesa. La eclosión de los dispositivos móviles ha propiciado el paso de las comunicaciones interlocales a las translocales, lo que ha supuesto e impuesto la necesidad del always on (siempre conectado).

La oferta de dispositivos también se ha diversificado. La cuarta pantalla puede adquirir la forma de teléfono móvil, pero también de otros aparatos como las PSPs (play station portable), las PDAs (personal digital assistant), smart-phones, iPhones... 
Estos dispositivos no son una simple prolongación del ordenador sino que presentan un comportamiento de consumo diferenciado. Según Hernández-García, Iglesias-Pradas, Chaparro-Peláez y Pascual-Miguel (2009), se podrían distinguir tres tipos de usos:

- repetitivo (consulta continua de la misma información, como las cotizaciones bursátiles o previsiones meteorológicas);

- de ocio (consultas que se realizan cuando se dispone de ratos de tiempo libre, por ejemplo al hacer un viaje en avión o en tiempos de espera -es el perfil de uso más similar al de la navegación web tradicional-); y

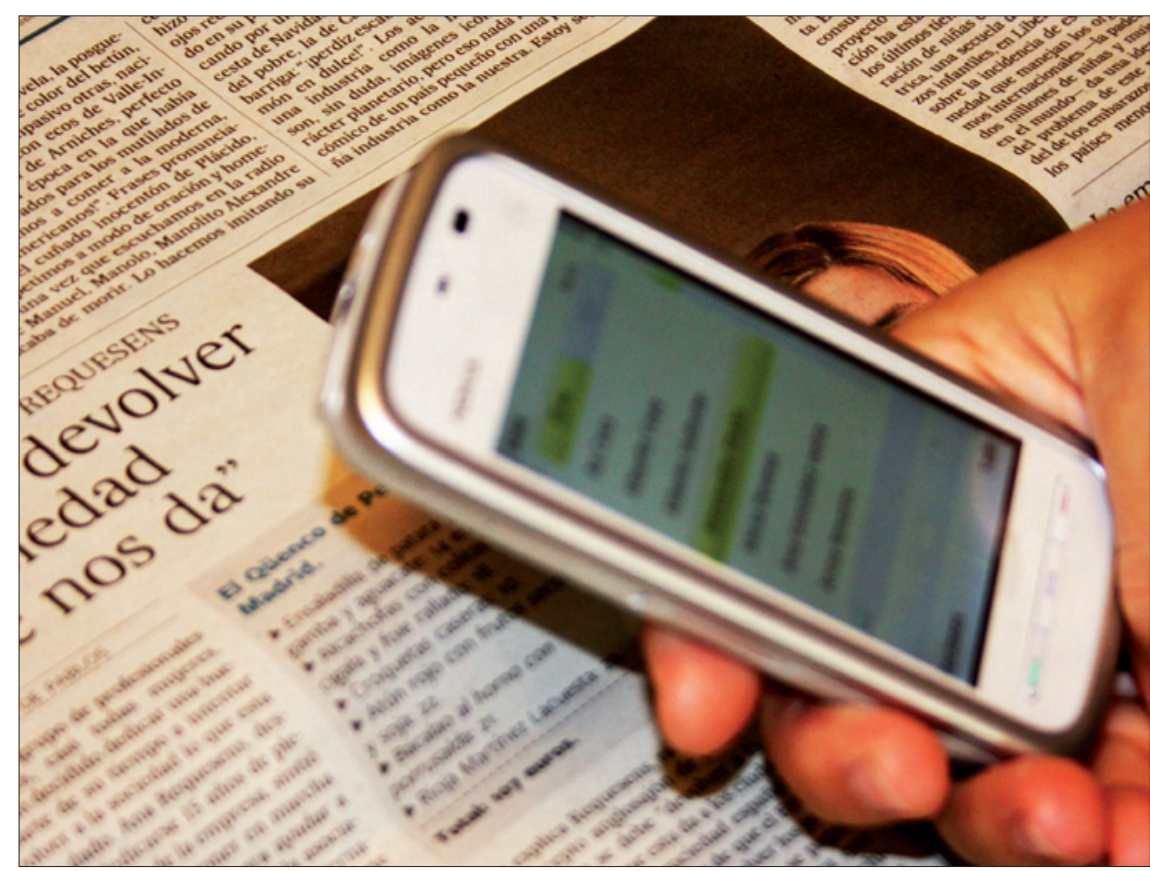

- urgente (búsquedas de información concreta y necesaria para llevar a cabo una actividad, por ejemplo, localizar un comercio, adquirir entradas para un espectáculo o buscar rutas hacia un punto de destino).

Este medio otorga al usuario un papel activo y decisivo. La conectividad pasa a depender de la persona, que adapta el terminal a sus preferencias en lo que respecta a sus contenidos y potencialidades. Nuevas formas de consumo implican también nuevas formas de plantear los contenidos. Supone personalizar, individualizar la comunicación, pues cada receptor tiene un número único y distinto al que se pueden asociar las preferencias y hábitos de uso. Todo ello representa un elemento interesante para las empresas de comunicación (Aguado; Martínez, 2006).

\section{"Nuevas formas de consumo implican también nuevas formas de plantear los contenidos"}

\section{Dispositivos móviles y convergencia mediática}

El desarrollo de software para la reproducción con calidad de textos y la evolución de los diferentes dispositivos móviles (ebooks, netbooks, PDAs, etc.), ha permitido la convergencia de diferentes funciones en un único aparato, cuyo mejor ejemplo es el teléfono móvil.

Según Fernández-Morales (2003, p. 79), en el futuro la telefonía móvil será el modelo dominante de conexión a internet, consiguiendo lo que no ha logrado el PC: que los usuarios paguen por los contenidos que se descargan. El abaratamiento de los terminales de última generación, especialmente en lo que se refiere a los móviles 3G o umts, los convierte en la tecnología propicia para el desarrollo de la prensa móvil. Estos teléfonos, salvando las limitaciones impuestas por el tamaño de la pantalla y el sistema de entrada de datos, pueden procesar el lenguaje xhtml así como el estilo css (cascading style sheets).

En este contexto tecnológico se inserta la aparición y relativa implantación del iPhone de Apple, que ha propiciado el despegue de la web móvil, y cuyo sistema de navegación ha supuesto la definición del concepto de "web única": una misma versión web independientemente del sistema de acceso (Cobo-Romaní; PardoKuklinski, 2007).

Acceder a un diario digital desde un dispositivo móvil es una experiencia nueva, diferente de la de un ordenador personal, que proporciona un consumo de información más allá de limitaciones temporales y espaciales. Un soporte idóneo que permite a los cibermedios responder a algunas de sus principales incógnitas (por ejemplo, sistema de financiación o adquisición de inversión publicitaria) en torno a su posicionamiento en un entorno altamente cambiante (Parra, 2008, p. 86).

En este sentido resulta imprescindible una concepción del ciberperiodismo que lleve implícita la incorporación de nuevos servicios en busca de una mayor viabilidad. "Los diarios y revistas que atraviesan dificultades para generar ingresos directos procedentes de los visitantes de sus sitios web tendrán oportunidad de cobrar por contenidos en móviles" (Fernández-Morales, 2003, p. 79). 
Desde las primeras iniciativas de información en el móvil como un sistema de avisos de actualización de contenidos por medio de sms (short message service), la telefonía móvil se ha posicionado como una alternativa rentable a la prensa online tradicional, con una serie de servicios añadidos en función de al menos dos segmentos de público: profesional y particular (García-De Diego et al., 2007, p. 261).

Para llevar a cabo con éxito el posicionamiento en esta cuarta pantalla resulta preciso conocer las características del nuevo canal, conjugando las limitaciones técnicas de los terminales con la versatilidad en la administración de contenidos y un diseño ad hoc. En efecto, la adecuación del diseño al contenido supone uno de los aspectos más valorados por el público para atender al acceso y a la credibilidad del cibermedio (Fogg; Soohoo; Danielson, 2002).

\section{"Los dispositivos móviles permiten un acceso a la información sin limitaciones temporales y espaciales"}

\section{Metodología}

El análisis empírico llevado a cabo en el presente trabajo tenía como cometido conocer las posibilidades de movilidad de la información que ofrecen los cibermedios. Para ello se han tomado como referencia aquellas páginas web auditadas por OJD Interactiva bajo la categoría Noticias e información, que representa el $35 \%$ de las sometidas al estudio de la Oficina de Justificación de la Difusión (un total de 361).

La muestra estuvo configurada por 127 unidades de análisis, en su mayoría diarios digitales y webs de otros medios de comunicación (76\%), además de otras páginas de información y servicios, como las de determinados sectores profesionales (información sectorial).

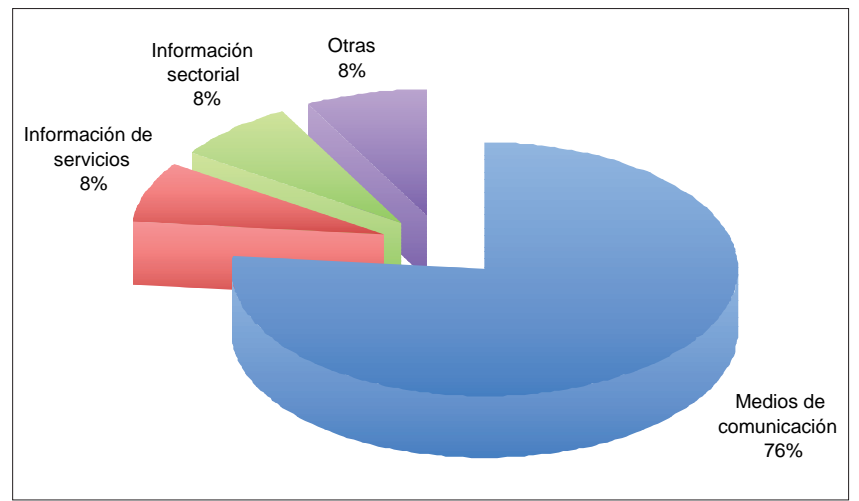

Gráfico 1. Composición de la muestra
Se han establecido tres variables de acceso a la información desde un dispositivo móvil.

- Existencia de un sistema de alertas sms.

- Versión para terminales móviles y/o para otro tipo de dispositivos móviles.

- Versión exclusiva para su acceso desde iPhones.

A partir de estas variables pretendemos concluir en qué medida las webs analizadas están aprovechando las posibilidades que ofrecen los diferentes dispositivos móviles para lograr la información everywhere. ¿Es la información móvil un proyecto de futuro o una realidad?

\begin{tabular}{|l|r|r|}
\hline \multicolumn{1}{|c|}{ Sistema de acceso a la información } & Sí & No \\
\hline Servicio de alertas por sms & 6 & 94 \\
\hline Contenidos adaptados a los teléfonos móviles & 11 & 89 \\
\hline $\begin{array}{l}\text { Contenidos adaptados a otro tipo de receptores } \\
\text { móviles }\end{array}$ & 4 & 96 \\
\hline Contenidos adaptados a iPhones & 8 & 92 \\
\hline
\end{tabular}

Tabla 1. Variables analizadas (\%)

\section{Alertas sms a móviles}

En la búsqueda de nuevas formas de financiación y mercado, los medios de comunicación y en particular los digitales han encontrado en los sms una importante fuente de ingresos. Los contenidos vehiculados se pueden clasificar en tres tipos:

- Descargas de audiovisuales en las que el usuario compra (vía sms) un contenido concreto (politonos, juegos...).

- Participación en concursos y promociones.

- Alertas al móvil, servicio al que el usuario se suscribe con la finalidad de obtener información actualizada.

En las webs analizadas el servicio de sms está vinculado fundamentalmente al entretenimiento (música, juegos, vídeos, horóscopo...) y es muy inferior el empleo de alertas informativas (estado de las carreteras, meteorología, bolsa, etc.).

Los datos sobre información de actualidad propiamente dicha muestran que apenas un 5,7\% de las páginas analizadas permite el envío de alertas informativas al terminal de los usuarios, las cuales se refieren generalmente a resultados de competiciones deportivas (tanto al resultado general como a la evolución de los hitos importantes de los encuentros).

Resulta destacable la escasa implantación de este servicio entre las webs de la muestra, especialmente en el caso de los medios digitales, dado que solamente un $8 \%$ ofrece alertas informativas vía sms. 
La tarificación de este servicio -pago por sms recibido- podría ser la principal causa de la ausencia de una oferta de sindicación de contenidos de información general, cosa que ha implicado una cierta especialización del servicio, dirigido a un mercado muy concreto (aficionados deportivos) y por el que no han apostado los cibermedios locales.

\section{"El servicio de sms está más vinculado al entretenimiento, y se usa menos que las alertas informativas"}

\section{Información de actualidad en la cuarta pantalla}

Las alertas de sms, a pesar de su escasa implantación, han generado en los usuarios la sensación de estar informados en cualquier momento y en cualquier lugar. No obstante el verdadero despegue de la información móvil ha tenido lugar con la implantación de la tecnología 3G, que ha posibilitado un servicio rápido y de calidad a la hora de navegar por la Web, además del abaratamiento de los terminales telefónicos.

En nuestro intento por conocer el grado de implantación de servicios adaptados a los dispositivos móviles, en las páginas web analizadas se han considerado tres categorías de prestación del servicio en función del aparato receptor: teléfonos móviles, otros dispositivos (PDAs, PSPs, etc.) e iPhones.

Al margen de la revolución social y económica que ha supuesto la aparición y avance de la telefonía móvil, su potencial aún no ha sido aprovechado por los medios digitales. Solamente el 11,3\% de los medios de comunicación analizados incorporan entre sus servicios contenidos adecuados para su recepción en los terminales móviles.

\section{"Sorprende el escaso porcentaje de medios que han incorporado la telefonía móvil a su plan de negocio"}

Pese a que los móviles $3 \mathrm{G}$ presentan una tecnología capaz de procesar el lenguaje xhtml y el estilo css, la muestra analizada todavía presenta una concepción tradicional de la web móvil. En efecto, la mayoría de medios consultados optan por ofrecer otra versión del sitio web, con características y dirección propias (el dominio $h t t p: / / m$.), en lugar de contenidos adaptados para su recepción y correcta lectura en las diferentes pantallas.

Independientemente de su concepción de web móvil, resulta sorprendente el escaso porcentaje de medios que han incorporado la telefonía móvil a su plan de negocio, descartando el enorme potencial que su implantación supone para las empresas informativas.

Además del teléfono móvil hay otro tipo de dispositivos con una tecnología adecuada para el acceso a la información online en cualquier momento y lugar. Desde la aparición de los primeros cibermedios se ha especulado con la posibilidad de crear un receptor portátil para acceder a los contenidos de la prensa digital. Los primeros prototipos como el Flat Panel (Roger Fidler) o el News Pad (El periódico de Catalunya), han sido complementados con la progresiva implantación de los lectores de ebooks (Kindle, iRex Iliad, PRS de Sony, $i P a d$ ) y las primeras iniciativas de contenidos informativos adecuados a estos formatos (Díaz-Noci, 2009).

Al margen de éstos, existen otros receptores con mayor implantación entre el público, como las citadas PSPs o las PDAs, cuyas características los hacen interesantes para la web móvil.

\section{"Se ha especulado con la posibilidad de crear un receptor portátil para acceder a los contenidos de la prensa digital”}

Como sucedía con la telefonía móvil, la presencia de contenidos online adecuados a estos soportes resulta prácticamente testimonial. Sólo cuentan con ellos el $4 \%$ de sitios (y un 3\% de cibermedios).

Por su parte el lanzamiento del iPhone, el terminal telefónico de Apple, ha supuesto una verdadera revolución en el sector. Ha incorporado un nuevo concepto de pantalla, táctil y de mayor tamaño, que ha permitido potenciar y mejorar la experiencia receptiva de la web móvil. Además este terminal ha adoptado un nuevo concepto de navegación más próximo a los estándares de la web convencional y por tanto ha promocionado la experiencia de la web única.

Estas potencialidades para la recepción de la información everywhere han favorecido la rápida acogida del iPhone por parte de los medios digitales, como una apuesta por la difusión de sus contenidos móviles.

En el marco de una reducida oferta de contenidos adaptados a la cuarta pantalla, el 8,24\% de los ciberme- 
dios cuentan con su propia versión para el iPhone, presencia que se puede considerar elevada si atendemos al $11 \%$ de medios digitales que ofertan información adecuada a los terminales de telefonía móvil.

\section{Conclusiones. Apuntes sobre información y movilidad en la sociedad red}

La eclosión de la telefonía móvil y la democratización de los diferentes tipos de dispositivos móviles (iPods, MP4s, lectores de ebooks, netbooks, PSPs, $P D A s$ ) han supuesto una auténtica revolución social. Este fenómeno, reforzado por el desarrollo de las redes wireless, ha incrementado las posibilidades de movilidad de la información y ha supuesto un paso más desde la web convencional a la everywhere.

A una sociedad móvil le corresponde una oferta informativa adaptada a un estilo de vida sin limitaciones de carácter temporal y geográfico. Se impone con fuerza el concepto de always on.

El estudio realizado nos ha permitido concluir que dichas posibilidades no están siendo suficientemente aprovechadas por las empresas informativas españolas. Unas empresas que en su redefinición actual deberían orientarse a los nuevos nichos de mercado que les ofrecen las TIC.

Por el momento se ha comprobado que las páginas informativas digitales utilizan la telefonía móvil como una línea de negocio lucrativa, mediante sms con contenidos de carácter lúdico (horóscopo, juegos, música...). Queda por explotar el sector informativo, para el que las páginas web analizadas apenas se hallan preparadas.

El lanzamiento al mercado del iPhone ha supuesto un revulsivo para los terminales convencionales, debido a la buena acogida de su diseño y de su experiencia de navegación. Esta tecnología, que supone un incremento en la calidad de la recepción de la información, podría imponerse en los contenidos móviles de los medios digitales ante la aparición de terminales con prestaciones similares. La definición y consolidación de un nuevo segmento de mercado podría conducir a las empresas periodísticas a adaptar sus contenidos a soportes móviles de altas prestaciones, sin tener que abandonar el concepto de web única.

Sin embargo los datos son concluyentes: la implantación de contenidos para dispositivos móviles en los cibermedios analizados es todavía muy escasa, y responde a una visión limitada de la Web y de sus capacidades.

\section{Bibliografía citada}

Aguado, Juan-Miguel; Martínez, Inmaculada J. "El proceso de mediatización de la telefonía móvil: de la interacción al consumo cultural". Zer, 2006, n. 20, pp. 319-343.

http://www.ehu.es/zer/zer20/zer20_19_aguado.pdf

Cobo-Romaní, Cristóbal; Pardo-Kuklinski, Hugo. Planeta Web 2.0. Inteligencia colectiva o medios fast food. Barcelona/México DF: Grup de Recerca d'Interaccions Digitals, Universitat de Vic. Flacso México, 2007. http://www.planetaweb2.net/

García-De-Diego, Antonio; Parra, David; Rojo, Pedro-Antonio. Tecnologías de la información en la producción periodística. Madrid: Universitas, 2007.

Díaz-Noci, Javier. "2018: ¿Diarios en dispositivos móviles? Libro electrónico, tinta electrónica y convergencia de la prensa impresa y digital”. El profesional de la información, 2009, v. 18, n. 3, pp. 301-307.

Fernández-Morales, Isabel. "Herramientas del periodista digital”. En: Pareja, Víctor-Manuel. Guía de internet para periodistas. Madrid: Centro de Información y Documentación Científica, CSIC, 2003, pp. 59-105.

Fogg, Brian J.; Soohoo, Cathy; Danielson, David. How do people evaluate a web site's credibility? Results from a large study. University of Stanford. http://www.consumerwebwatch.org/dynamic/web-credibility-reportevaluate.cfm

Fundación Telefónica. La sociedad de la información en España 2009 http://e-libros.fundacion.telefonica.com/sie09/aplicacion_sie.html

Hernández-García, Ángel; Iglesias-Pradas, Santiago; Chaparro-Peláez, Julián; Pascual-Miguel, Félix-José. "La web en el móvil: tecnologías y problemáticas”. El profesional de la información, 2009, v. 18, n. 2, pp. 137144.

Parra, David. "Ciberperiodismo móvil: el peso específico de la cuarta pantalla en el panorama informativo internacional". Revista RE-Presentaciones periodismo, comunicación y sociedad, 2008, n. 4, pp. 73-91.

\section{Carmen Costa-Sánchez, María-Teresa Piñeiro-Otero.} Facultade de Ciencias de la Comunicación, Campus de Elviña, 15071 A Coruña.

carmen.costa@udc.es

teresa.pineiro@udc.es 